\title{
FINE NEEDLE ASPIRATION OF THYROID AS A SCREENING TEST- DIAGNOSTIC ACCURACY, DISCREPANCIES AND PITFALLS- STUDY OF 1175 PATIENTS IN A TERTIARY CARE CENTRE
}

\author{
Kumari Ajitha1 ${ }^{1}$ Asha P. Punnoose², Mary Raju³, Sany Philip ${ }^{4}$, Alice David5 \\ ${ }_{1}^{1}$ Professor and HOD, Department of Pathology, Believers Church Medical College, Thiruvalla, Kerala, India. \\ ${ }^{2}$ Assistant Professor, Department of Pathology, Believers Church Medical College, Thiruvalla, Kerala, India. \\ ${ }^{3}$ Assistant Professor, Department of Pathology, Believers Church Medical College, Thiruvalla, Kerala, India. \\ ${ }^{4}$ Lecturer, Department of Pathology, Believers Church Medical College, Thiruvalla, Kerala, India. \\ ${ }^{5}$ HOD, Medical Research, Department of Pathology, Believers Church Medical College, Thiruvalla, Kerala, India.
}

\section{ABSTRACT}

\section{BACKGROUND}

Fine needle aspiration cytology of thyroid plays a key role in the preoperative differentiation of benign from malignant nodules. The treatment decision is greatly influenced by the cytological diagnosis. The current study was done to assess the diagnostic accuracy, discrepancies and pitfalls when blind FNACs of thyroid is employed as a screening test and also to analyse the causes of diagnostic discrepancies so that improvement measures can be undertaken. Thyroid diseases are encountered very commonly in everyday clinical practice especially in females. However, a majority of the thyroid nodules are asymptomatic, and only 5 to $10 \%$ of the nodules turn out to be malignant after surgical excision.

\section{METHODS}

We analysed 1175 FNACs from our centre using descriptive study design. These were classified based on The Bethesda System of Reporting Thyroid Cytology (TBSRTC). 132 patients who underwent surgery from the 6 different categories were further analysed to study the diagnostic accuracy, discrepancies and pitfalls.

\section{RESULTS}

Sensitivity was $64.7 \%$, specificity was $97.1 \% \%$, PPV was $78.5 \%$, NPV was $94.4 \%$ and diagnostic accuracy was $92.6 \%$.

\section{CONCLUSIONS}

Blind FNAC has its own limitations. Image guided aspiration will be a better option to increase the yield of diagnostic material and for better targeting of the lesion. Ancillary techniques also can also be employed. After the introduction of the TBSRTC system of reporting for thyroid cytopathology, it is seen that there is a dramatic decrease in the rate of unwanted surgeries for thyroid lesions and among the surgically resected cases, malignancy rates have increased. The increased malignancy rates can be attributed to the careful selection of patients for surgery based on TBSRTC categories.

\section{KEYWORDS}

Thyroid Nodule, TBSRTC, Aspiration Cytology, Histopathology, Sensitivity, Specificity

HOW TO CITE THIS ARTICLE: Ajitha K, Punnoose AP, Raju M, et al. Fine needle aspiration of thyroid as a screening test- diagnostic accuracy, discrepancies and pitfalls- study of 1175 patients in a tertiary care centre. J. Evolution Med. Dent. Sci. 2019;8(28):22432246, DOI: $10.14260 /$ jemds/2019/491

\section{BACKGROUND}

Thyroid diseases are encountered very commonly in everyday clinical practice especially in females. However, majority of the thyroid nodules are asymptomatic, and only 5 to $10 \%$ of the nodules turn out to be malignant after surgical excision.[1] FNAC is a cost effective, easy to apply method widely used as a screening test for all thyroid swellings of any age group in both sexes. Blind FNAC without any image guidance is still widely used as the primary diagnostic tool for any type of thyroid swelling. After the introduction of TBSRTC, the distinction between neoplastic and non-neoplastic conditions based on cytological findings is made clearer and this has helped the clinicians to avoid unwanted surgeries.[2]

'Financial or Other Competing Interest': None.

Submission 07-05-2019, Peer Review 29-06-2019,

Acceptance 04-07-2019, Published 15-07-2019.

Corresponding Author:

Kumari Ajitha,

Professor and HOD, Department of Pathology,

Believers Church Medical College, Thiruvalla, Kerala, India.

E-mail: ajithakdr@gmail.com

DOI: $10.14260 /$ jemds/2019/491

\section{(c) $(1) \ominus$}

All patients in the suspicious categories and frankly malignant categories are usually taken for surgery. The decision for surgical treatment in the non-malignant TBSRTC categories is based on clinical suspicion, radiological findings and also due to cosmetic reasons. FNAC combined with TBSRTC as a screening test is at present considered to be the most accurate and preliminary diagnostic modality based on which clinical recommendation for surgical management is made possible. But it has certain limitations as well. There are certain grey zones in thyroid cytology which often leads to discrepancies between cytological and histopathological diagnosis. Overlapping cytomorphological features often lead to overdiagnosis or under diagnosis of malignancy.[3]

\section{METHODS}

The descriptive study was conducted on 1175 patients who underwent fine needle aspiration cytology as a screening test for thyroid lesions during the period of 2016-2018. Patients from all age groups and both sexes were included. Fine needle aspirations were done by the pathologist. Aspirated material was placed on glass slides and smears were prepared and immediately transferred to fixative. 


\begin{tabular}{|c|c|c|}
\hline TBSRTC Category & $\begin{array}{c}\text { Number in Each } \\
\text { Category }\end{array}$ & $\begin{array}{c}\text { Percentage of Each } \\
\text { Category }\end{array}$ \\
\hline Category I & 113 & 9.6 \\
\hline Category II & 979 & 83.3 \\
\hline Category III & 24 & 2.0 \\
\hline Category IV & 16 & 1.4 \\
\hline Category V & 22 & 1.9 \\
\hline Category VI & 21 & 1.8 \\
\hline Total & $\mathbf{1 1 7 5}$ & $\mathbf{1 0 0}$ \\
\hline \multicolumn{2}{|c|}{ Table 1. Cytology Results as per TBSRTC Criteria } \\
\hline
\end{tabular}

\begin{tabular}{|c|c|c|c|}
\hline $\begin{array}{c}\text { TBSRTC } \\
\text { Category }\end{array}$ & $\begin{array}{c}\text { No. of Surgery in Each } \\
\text { Category }\end{array}$ & $\begin{array}{c}\text { HPR } \\
\text { Benign }\end{array}$ & $\begin{array}{c}\text { HPR } \\
\text { Malignant }\end{array}$ \\
\hline I & 10 & 9 & 1 \\
\hline II & 108 & 102 & 6 \\
\hline III & 3 & 2 & 1 \\
\hline IV & 1 & 0 & 1 \\
\hline V & 7 & 1 & 6 \\
\hline VI & 3 & 0 & 3 \\
\hline Total & 132 & 114 & \\
\hline \multicolumn{4}{|c|}{ Table 2. Results of Resected Specimens } \\
\hline
\end{tabular}

\begin{tabular}{|c|c|c|}
\hline TBSRTC Category & Total No. & Histological Types of Malignancy \\
\hline I & 1 & PTC-classical \\
\hline II & 6 & PTC classical (4),Follicular variant(2) \\
\hline III & 1 & Follicular variant of PTC -multifocal \\
\hline IV & 1 & Follicular Carcinoma \\
\hline V & 6 & $\begin{array}{c}\text { PTC - Classical (4) } \\
\text { PTC - Follicular variant (1) } \\
\text { PTC - Oncocytic variant (1) }\end{array}$ \\
\hline VI & 3 & $\begin{array}{r}\text { PTC - Classical (2) } \\
\text { PTC - Oncocytic variant (1) }\end{array}$ \\
\hline \multicolumn{2}{|c|}{ Table 3. Histological Types of Malignancy } \\
\hline
\end{tabular}

\begin{tabular}{|c|c|c|c|c|}
\hline & & \multicolumn{3}{|c|}{ Histopathology } \\
\hline & & +ve & $-v e$ & \\
\hline \multirow{3}{*}{ Cytology } & + ve & 11 & 3 & 14 \\
\hline & -ve & 6 & 102 & 108 \\
\hline & & 17 & 105 & 122 \\
\hline \multicolumn{3}{|c|}{ Observed Agreement } & \multicolumn{2}{|c|}{$92.6 \%$} \\
\hline \multicolumn{3}{|c|}{ Expected Agreement } & \multicolumn{2}{|c|}{$77.8 \%$} \\
\hline \multicolumn{3}{|c|}{ Cohen's Kappa } & \multicolumn{2}{|c|}{$66.8 \%$} \\
\hline \multicolumn{3}{|c|}{ SE } & \multicolumn{2}{|c|}{$10.7 \%$} \\
\hline \multicolumn{3}{|c|}{$95 \% \mathrm{CI}$} & \multicolumn{2}{|c|}{$45.9 \%-87.7 \%$} \\
\hline \multicolumn{5}{|c|}{ Table 4. Comparison of TBSRTC to HPR } \\
\hline
\end{tabular}

After a period of fixation, these smears were stained by Papanicolaou's method. In each case two air dried smears were also prepared. These air-dried smears were stained with Giemsa stain. Evaluation was done by the Bethesda system of reporting thyroid cytopathology (TBSRTC)

Diagnostic category was given to each case based on the Bethesda system. These cases were followed up and cases which were operated in this hospital were analysed as to the diagnostic accuracy, discrepancies and the pitfalls in diagnosis. All discordant cases were reviewed and the possible causes for the discrepancy were analysed.

\section{RESULTS}

Out of the 1175 cases $113(9.6 \%)$ were categorised as TBSRTC I, $979(83.3 \%)$ as II, $24(2 \%)$ as III, $16(1.4 \%)$ as IV, $22(1.9 \%)$ as $\mathrm{V}$ and $21(1.8 \%)$ as category VI. Cytodiagnosis as per TBSRTC criteria is shown in Table I. In the follow up of the 1175 FNACs done, the number of cases operated in our hospital was 132. Among these 18 patients were males and 114 were females with a male to female ratio of approximately $1: 6$ (male $13.6 \%$ and $86.4 \%$ ). Age of the patients ranged from 18-76. Of these 132 patients 18 cases proved to be malignant by histopathology whereas the remaining 114 cases were benign. These patients belonged to the different TBSRTC categories mostly from those in the malignant or suspicious for malignant category as shown in Table 2. Patients from different categories who opted for surgery elsewhere were not included in this study due to difficulty in follow up.
132 patients belonging to different categories underwent surgery in this hospital. 10 cases from the non-diagnostic category were taken for surgery, 104 cases from category II, 6 cases from category III, 2 cases from category IV, 7 cases from category $\mathrm{V}$ and 3 cases from category VI. (Table-2).

Histological types of malignancy were papillary thyroid carcinoma (PTC) classical (11), PTC follicular variant (4), PTC oncocytic variant (2) and follicular carcinoma (1) as shown in Table 3.

For all statistical analysis non-diagnostic category was not considered. Category II was taken as cytologically benign. Category III, IV and V were taken as cytologically indeterminate category and category $\mathrm{VI}$ as cytological malignant. Of the 122 cases, 102 were true negative (83.6\%), 11 were true positive (9\%), 6 false negative (4.9\%) and 3 false positive. $(2.5 \%)$ as shown in Table 4 . Sensitivity $64.7 \%$, specificity $97.1 \%$ \%, PPV 78.5\%, NPV 94.4\%\%. Although the observed diagnostic accuracy (or agreement) was $92.6 \%$, the expected agreement was $77.8 \%$. The Cohen's Kappa was only 66.85 with $95 \%$ Confidence Interval (45.9\% - 87.7\%) as shown in Table 4.

\section{DISCUSSION}

Among the initial 1175 patients on whom aspiration was done a total of $113(9.6 \%)$ were classified as non-diagnostic. Various other studies have reported a wide range varying from 1.6 to $20 \%$ in the non-diagnostic category.[4,5,6,7] Many of the cases in our study group were included in the non-diagnostic category because of the heavy blood contamination of the smears thereby obscuring the morphology of the cells by clotted blood. Thyroid gland being a highly vascular organ, the skill of the person doing the FNACs as well as the technician who prepare and stain the smears play a major role in procuring good quality smears. Technical expertise is of paramount importance so that a cellular aspirate is obtained wherever possible and optimal utilization of the material is made possible. Among the 122 cases taken for surgery 102 (83.6\%) cases turned out to be true negative (Benign) on histopathology. Previous studies have reported a benign cytology diagnosis in $50 \%$ to $90 \%$ of the specimens (average, $70 \%)_{.[8,9,10,11,12]}$ Benign entities in our study included mostly multinodular goitre along with Hashimoto's' thyroiditis as proved by histopathological examination. Malignancy risk for category II as per the Bethesda system of reporting is expected to be $0-3 \%,{ }^{[2]}$ whereas in our case it was nearly $5 \%$ (False negative). Patients with benign cytology are usually asked to undergo surgical management only when other clinical risk factors are present. There are studies which reported still higher false negative rates reaching up to $14 \% .[13,14,15,16,17,18]$ Still other studies have reported false negative rates varying from 1.5 to $11.5 \%{ }^{[19,20,21]}$ These data published in literature suggest that follow up of cytological benign cases at 6 months interval by repeated FNAC (As per the TBSRTC recommendation) may not be adequate in all cases.

A very important cause of a false negative diagnosis is follicular variant of papillary carcinoma where the cytodiagnosis has to be made solely on nuclear features which can often be subtle and focal. But in our study, among the false negative cases there were only two cases of follicular variant of papillary carcinoma while the remaining 4 cases were classical variants. We missed the diagnosis of malignancy because of the prominent cystic changes, paucity of nuclear 
features and the absence of true papillary formations in the smears. False negative cytology diagnosis can also occur when the size of the target lesions are small. Reporting on suboptimal samples also contribute to false negative diagnosis. Image guided FNAC is a better option in such cases so that the lesion is not missed, and adequate material is obtained.

Positive cytology findings followed by a negative histopathology result can have serious implications and is the most important pitfall of thyroid cytopathology. The falsepositive rate of FNAC results in thyroid cancer has been reported as $2-10 \%{ }^{[22,23,24]}$ In our study, there were $3(2.5 \%)$ such false positive results. Among this one case was categorised as suspicious of malignancy (Category $\mathrm{V}$ according to Bethesda system) based on the presence of papillary formations without nuclear features of malignancy and this case on histological examination showed cystic degeneration with areas of papillary hyperplasia. According to the Bethesda system, when one characteristic feature of papillary carcinoma alone is present in the smears it is reported as suspicious of malignancy and on resection only 60-75 \% turn out to be malignant while the rest are benign. In the other 2 cases the smears were sparsely cellular and were labelled as category III based on nuclear atypia and the presence of hurthle cells. We advised repeat FNAC in these patients, but the clinicians opted for surgery and on histopathology proved to be Hashimoto's thyroiditis. It is a well-known fact that chronic thyroiditis of any type may mimic carcinoma thyroid in cytologic smears leading on to false positive diagnosis. This is due to the occurrence of cytological features of papillary carcinoma in these lesions. Studies show that prevalence of chronic thyroiditis is higher among patients with false positive FNA results than in those with confirmed papillary carcinoma.[25] The clinicians should also be aware of this and necessary patient counselling before surgery becomes important. The occurrence of papillary carcinoma in a case of Hashimoto's thyroiditis is not rare and, in such cases, the cytological diagnosis is often challenged by atypical cytological features and lymphocytic infiltration.[26]

In this study $11(9 \%)$ cases were true positive as evidenced from histopathology. Six of these patients were from category V, 3 from category VI and one each from category IV \& III, The histological types of malignancy in these cases were as shown in Table 3. The only one case from category IV who underwent surgery here turned out to be Follicular carcinoma. There were no medullary carcinoma in our study group and the only case of anaplastic carcinoma diagnosed cytologically was treated without surgery.

The overall sensitivity of thyroid FNAC in this study is just $64.7 \%$, specificity is $97.1 \%$. This is comparable to the already reported results of $65-99 \%$ and $72-100 \%$ respectively.[27,22,23,24] We got a PPV 78.5\%, NPV 94.4\%\%.The positive predictive value of a malignant FNA cytology result is 97-99\% according to the Bethesda system whereas in our study the positive predictive value was only $78.5 \%$. In our study we got a diagnostic accuracy of $92.6 \%$ whereas accuracy up to $97 \%$ has been reported in literature.[28] Preoperative diagnosis of thyroid nodules by blind FNAC, though widely used in most of the centres is not completely free of pitfalls. Even though the accuracy rate of FNA is high the reporting pathologist should be well aware of the pitfalls so as to avoid false positive/ negative diagnoses. There are certain cytomorphological features which may be seen in both benign and malignant conditions especially in papillary thyroid carcinoma leading to challenges in the diagnosis. Blind FNAC though used even now as a preliminary screening test in most of the institutions, the main limitations are related to lack of operator skill contributing to non-diagnostic aspirates, and non-availability of molecular techniques. Adequate sampling is very essential and for this aspirates should be obtained from multiple sites of the lesion or nodules. Rapid onsite evaluation of the material can help in assessing the adequacy. Wherever possible US guided FNAC can be done as it is the method of choice for selecting the nodules for the procedure[29,30]

\section{CONCLUSIONS}

After the introduction of the TBSRTC system of reporting for thyroid cytopathology, it is seen that there is a dramatic decrease in the rate of unwanted surgeries for thyroid lesions and among the surgically resected cases, malignancy rates have increased. The increased malignancy rates can be attributed to the careful selection of patients for surgery based on TBSRTC categories. Increasing incidence of thyroid cancer among our population is another reason. In the present study, malignancy rate was $13.6 \%$. This is considerably higher and many of the studies during last one or two decades have shown an ever-increasing incidence of thyroid cancer worldwide. This increase has been related to increased detection of subclinical cases and is not considered as an increase of true occurrence of thyroid cancer.[31]

\section{REFERENCES}

[1] Bomeli SR, LeBeau SO, Ferris RL. Evaluation of a thyroid nodule. Otolaryngol Clin North Am 2010;43(2):229-38.

[2] Cibas ES, Ali SZ. The Bethesda system for reporting thyroid cytopathology. Thyroid 2009;19(11):1159-65.

[3] Guhamallick M, Sengupta S, Bhattacharya NK, et al. Cytodiagnosis of thyroid lesions-usefulness and pitfalls: a study of 288 cases. J Cytol 2008;25(1):6-9.

[4] Pandey P, Dixit A, Mahajan NC. Fine-needle aspiration of the thyroid: a cytohistologic correlation with critical evaluation of discordant cases. Thyroid Res Pract 2012;9(2):32-9.

[5] Bagga PK, Mahajan NC. Fine needle aspiration cytology of thyroid swellings: How useful and accurate is it? Indian J Cancer 2010;47(4):437-42.

[6] Esmaili HA, Taghipour H. Fine-needle aspiration in the diagnosis of thyroid disease: an appraisal in our institution. Article ID 912728, ISRN Pathology 2012;2012:1-4.

[7] Ali SZ. Thyroid cytopathology: Bethesda and beyond. Acta Cytol 2011;55(1):4-12.

[8] Goellner JR, Gharib H, Grant CS, et al. Fine needle aspiration cytology of the thyroid, 1980 to 1986 . Acta Cytol 1987;31(5):587-90.

[9] Singer PA. Evaluation and management of the solitary thyroid nodule. Otolaryngol Clin North Am 1996;29(4):577-91.

[10] Baloch ZW, Sack MJ, Yu GH, et al. Fine-needle aspiration of thyroid: an institutional experience. Thyroid 1998;8(7):565-9. 
[11] Caruso D, Mazzaferri EL. Fine needle aspiration biopsy in the management of thyroid nodules. Endocrinologist 1991;1(3):194-202.

[12] Gharib H, Goellner JR. Fine-needle aspiration biopsy of the thyroid: an appraisal. Ann Intern Med 1993;118(4):282-9.

[13] Broome JT, Solorzano CC. The impact of atypia/follicular lesion of undetermined significance on the rate of malignancy in thyroid fine-needle aspiration: evaluation of the Bethesda system for reporting thyroid cytopathology. Surgery 2011;150(6):1234-41.

[14] Richmond BK, O'Brien BA, Mangano W, et al. The impact of the Bethesda system for reporting thyroid cytopathology on the surgical treatment of thyroid nodules. Am Surg 2012;78(6):706-10.

[15] Negro R, Piana S, Ferrari M, et al. Assessing the risk of false-negative fine-needle aspiration cytology and of incidental cancer. Endocr Pract 2013;19(3):444-50.

[16] Renshaw A. An estimate of risk of malignancy for a benign diagnosis in thyroid fine-needle aspirates. Cancer Cytopathol 2010;118(4):190-5.

[17] Yang J, Schnadig V, Logrono R, et al. Fine-needle aspiration of thyroid nodules: a study of 4703 patients with histologic and clinical correlations. Cancer Cytopathol 2007;111(5):306-15.

[18] Chernyavsky VS, Shanker BA, Davidov T, et al. Is one benign fine needle aspiration enough? Ann Surg Oncol 2012;19(5):1472-6.

[19] Hamburger JI. Diagnosis of thyroid nodules by fine needle biopsy: use and abuse. J Clin Endocrinol Metab 1994;79(2):335-9.

[20] Giuffrida D, Gharib H. Controversies in the management of cold, hot and occult thyroid nodules. Am J Med 1995;99(6):642-50.

[21] Hall TL, Layfield LJ, Philippe A, et al. Sources of diagnostic error in fine needle aspiration of the thyroid. Cancer 1989;63(4):718-25.
[22] Yoon JH, Kwak JY, Moon HJ, et al. The diagnostic accuracy of ultrasound-guided fine-needle aspiration biopsy and the sonographic differences between benign and malignant thyroid nodules $3 \mathrm{~cm}$ or larger. Thyroid 2011;21(9):993-1000.

[23] Lew JI, Snyder RA, Sanchez YM, et al. Fine needle aspiration of the thyroid: correlation with final histopathology in a surgical series of 797 patients. J Am Coll Surg 2011;213(1):188-95.

[24] Sclabas GM, Staerkel GA, Shapiro SE, et al. Fine-needle aspiration of the thyroid and correlation with histopathology in a contemporary series of 240 patients. Am J Surg 2003;186(6):702-10.

[25] Yi KI, Ahn S, Park DY, et al. False-positive cytopathology results for papillary thyroid carcinoma: a trap for thyroid surgeons. Clin Otolaryngol 2017;42(6):115360.

[26] Kapan M, Onder A, Girgin S, et al. The reliability of fineneedle aspiration biopsy in terms of malignancy in patients with Hashimoto thyroiditis. Int Surg 2015;100(2):249-53.

[27] Sidawy MK, Del Vecchio DM, Knoll SM. Fine-needle aspiration of thyroid nodules: correlation between cytology and histology and evaluation of discrepant cases. Cancer 1997;81(4):253-9.

[28] Sharma C. Diagnostic accuracy of fine needle aspiration cytology of thyroid and evaluation of discordant cases. J Egypt Natl Canc Inst 2015;27(3):147-53.

[29] Gharib H, Papini E. Thyroid nodules: clinical importance, assessment and treatment. Endocrinol Metab Clin North Am 2007;36(3):707-35.

[30] Gharib H, Papini E, Paschke R, et al. American Association of Clinical Endocrinologists, Associazione Medici Endocrinologi and European Thyroid Association Medical guidelines for clinical practice for the diagnosis and management of thyroid nodules: executive summary of recommendations. Endocr Pract 2010;16(3):468-75.

[31] Davies L, Welch HG. Increasing incidence of thyroid cancer in the United States, 1973-2002. JAMA 2006;295(18):2164-7. 